\title{
Waterflooding and consolidation of reservoir chalk - effect on porosity and Biot's coefficient
}

Gram, Tobias B.; Ditlevsen, Frederik P.; Mosegaard, Klaus; Fabricius, Ida Lykke

\section{Published in:}

Geophysical Prospecting

Link to article, DOI:

10.1111/1365-2478.13047

Publication date:

2021

Document Version

Peer reviewed version

Link back to DTU Orbit

Citation (APA):

Gram, T. B., Ditlevsen, F. P., Mosegaard, K., \& Fabricius, I. L. (2021). Waterflooding and consolidation of reservoir chalk - effect on porosity and Biot's coefficient. Geophysical Prospecting, 69(3), 495-513. https://doi.org/10.1111/1365-2478.13047

\section{General rights}

Copyright and moral rights for the publications made accessible in the public portal are retained by the authors and/or other copyright owners and it is a condition of accessing publications that users recognise and abide by the legal requirements associated with these rights.

- Users may download and print one copy of any publication from the public portal for the purpose of private study or research.

- You may not further distribute the material or use it for any profit-making activity or commercial gain

- You may freely distribute the URL identifying the publication in the public portal 
Water-flooding and consolidation of reservoir chalk - effect on porosity and Biot's coefficient.

Tobias B. Gram ${ }^{1,2}$, Frederik P. Ditlevsen ${ }^{3}$, Klaus Mosegaard ${ }^{1}$ and Ida L. Fabricius ${ }^{2 *}$

${ }^{1}$ University of Copenhagen, Niels Bohr Institute, DK-2100 Copenhagen Ø; Denmark.

${ }^{2}$ Technical University of Denmark, Department of Civil Engineering, Brovej 118, DK-2800

Kongens Lyngby, Denmark.

${ }^{3}$ Geo, Maglebjergvej 1, DK-2800 Kongens Lyngby, Denmark.

*E-mail: ilfa@byg.dtu.dk.

Key Words: compaction, carbonate, rock physics

\begin{abstract}
Improved oil recovery from chalk reservoirs by water-flooding may cause mechanical weakening and change in elasticity. Confined compressive strength testing of chalk from a North Sea reservoir was done in water-saturated and in oil-saturated condition. During testing elastic wave velocities were sampled by ultrasonic transducers, so that subsequently Biot's coefficient could be modelled. The porosity declined via an "elastic phase", a "transitional phase", an "elastoplastic phase", and a "strain hardening phase", but Biot's coefficient indicates that these terms may be partly misleading. In the "elastic phase" porosity and Biot's coefficient decreases, indicating elastoplastic deformation. In the "transitional phase" Biot's coefficient increases as a reflection of breaking contact cement (pore collapse), whereas
\end{abstract} Biot's coefficient remain stable in the "elastoplastic phase" indicating elastic deformation on the virgin curve. Plastic deformation takes place during phases of creep, where both porosity This article has been accepted for publication and undergone full peer review but has not been through the copyediting, typesetting, pagination and proofreading process, which may lead to differences between this version and the Version of Record. Please cite this article as doi: 10.1111/1365-2478.13047.

This article is protected by copyright. All rights reserved. 
Gram et al.

and Biot's coefficient decrease. Similarly, in the "strain hardening phase", both porosity and Biot's coefficient decrease as a reflection of elastoplastic deformation. For chalk with $45 \%-$ $47 \%$ porosity, the "transitional phase" begins at $8 \mathrm{MPa}$ axial stress when water-saturated and at $12 \mathrm{MPa}$ when oil-saturated. For chalk with $41 \%-43 \%$ porosity the corresponding stresses are $16 \mathrm{MPa}$ and $20 \mathrm{MPa}$. For chalk with $32 \%-36 \%$ porosity the corresponding stresses are 23 $\mathrm{MPa}$ and $31 \mathrm{MPa}$.

Chalk samples with irreducible water-saturation and movable oil were water-flooded. They yield at stresses close to corresponding oil-saturated samples, but after flooding show compaction trends not significantly different from the water-saturated samples. Waterflooding promotes pore collapse as reflected in an increasing Biot's coefficient. The consequent softening effect on acoustic impedance is small as compared to the effect of increasing fluid density. With respect to 4D seismic, water-flooding causes distinctly higher acoustic impedance and Poisson's ratio irrespective of compaction.

\section{INTRODUCTION}

Water-flooding is a common improved oil recovery method, which has been reported to cause increased subsidence of chalk reservoirs in spite of increasing pore pressure (Hermansen et al. 2000, Nagel 2001, Doornhof et al., 2006). In order to evaluate the consequences of water-flooding for effective stress and reservoir stiffness, and to achieve correct interpretation of 4D seismic data, information on compaction behaviour and elastic wave velocity is needed. Rock stiffness describes the resistance to elastic deformation and is typically described in terms of elastic moduli. Effective stress is defined as the part of the total stress (external applied load) that governs the elastic deformation of a porous rock (Biot 1941). During confined uniaxial compressive strength testing, a sample suffers uniaxial 
Gram et al.

strain, so that the deformation is anisotropic. Based on Biot's equations, Alam et al. (2012) showed that during uniaxial strain of an isotropic material, Biot's coefficient is still as defined for isotropic stress, and the vertical effective stress, $\sigma_{z}$ ', can be expressed as:

$\sigma_{\mathrm{z}}^{\prime}=\sigma_{\mathrm{z}}-\alpha P_{\mathrm{p}}$

where $\sigma_{\mathrm{z}}$ is the total vertical stress caused by the overburden, $P_{\mathrm{p}}$ is the pore pressure, and $\alpha$ is Biot's coefficient. In the case of an isotropic linear elastic porous rock, Biot \& Willis (1957) showed that Biot's coefficient in equation 1 is given as

$\alpha=1-K_{\text {dry }} / K_{\mathrm{m}}$

Here $K_{\mathrm{dry}}$ and $K_{\mathrm{m}}$ denote the elastic bulk modulus of respectively the dry porous rock frame and the solid constituting the frame. $K_{\mathrm{m}}$ is estimated from the bulk modulus of the constituting minerals. Skempton (1961) gives a qualitative physical interpretation of Biot's coefficient as an area ratio, where $\alpha$ is linked to cementation and the packing of particles, so that Biot's coefficient approaches one for minimum particle contact and decreases with increasing contact area among particles.

Although chalks in some cases have been found to be anisotropic (e.g. Talesnick et al. 2001), they are not universally so: repeated initial loading of North Sea chalk has been found to cause initial anisotropy to practically vanish (Hickman 2004). This indicates that apparent anisotropy in otherwise massive chalk can be caused by exhumation and formation of horizontal micro cracks. During production of hydrocarbons by draw down, the pore pressure decreases, and for North Sea chalk fields the reservoir may be assumed to consolidate in a close to uniaxial strain geometry (Plischke 1994, Kristiansen 1998).

Kågeson-Loe et al. (1993) describe how the internal fabric changes during consolidation ("uniaxial strain" or "K $\mathrm{K}_{0}$-testing") of chalk. In accordance with normal practice, they describe 
Gram et al.

an initial "elastic phase" followed by a "transitional phase" defined by double yield points, where elasticity of the chalk is lost at the first yield point before significant strain sets in after the second yield point. After this second yield point, the chalk enters the "elastoplastic phase" and supposedly consolidates as a granular frictional material, and while consolidation advances, at some stage a stiffening (strain hardening) sets in (Fig. 1). During uniaxial compaction, yield is expected to take place through development of compaction bands (e.g. Baud et al. 2009), and Gaviglio et al. (2009) accordingly observed failure planes in chalk outcrops to be bounded by narrow zones of compaction. From tests on chalk from the Ekofisk field, Azeemuddin et al. (2001) found that Biot's coefficient for Ekofisk chalk was only slightly stress-sensitive, but decreases with increasing deviatoric stress as would be the case during $\mathrm{K}_{0}$-testing. They also found that Biot's coefficient predicted from static stress-strain curves is larger than that derived from density and velocities of elastic waves. In the present paper we will address the type of deformation during consolidation by including monitoring data on Biot's coefficient.

The observation that water-saturated chalk has lower shear modulus and is weaker than dry or oil-saturated chalk has been discussed from several angles in the last 25 years. Proposed mechanisms involve: capillary effects (Schroeder et al. 1998), chemical dissolution (e.g. Madland et al. 2006), difference in kinematic viscosity among fluids (Andreassen and Fabricius 2010), electrical repulsion among calcite particles (Megawati et al. 2013, Nermoen et al. 2018, Meireles et al. 2020), reactivation of fault planes (Christensen et al. 2003), and lower surface energy of wetted calcite as compared to non-wetted calcite (Røyne et al. 2011, Voake et al. 2019). In order to discuss water-weakening and effects of water-flooding of chalk, the present paper addresses results from consolidation tests on nine chalk samples from 
Gram et al.

the Danish North Sea. The samples cover the porosity range $32 \%$ to $47 \%$ and were tested as water-saturated, oil-saturated or at irreducible water-saturation followed by water-flooding. Possible water-weakening effects and effects of water-flooding were discussed in terms of porosity and Biot's coefficient derived from ultrasonic data. For description of elastic consequences of testing, Biot's coefficient is preferred over elastic bulk modulus because it describes stiffness normalized for mineralogy (equation 2). The ultrasonic data can be used in calculating Poisson's ratio and acoustic impedance, so that each sample can be tracked on a rock physics template.

\section{GEOLOGICAL SETTING}

The studied samples are from a gas and oil-bearing chalk reservoir in the Danish North Sea. The reservoir belongs to the Late Cretaceous and Paleocene Chalk Group (e.g. Surlyk et al. 2003). The field is located in the central North Sea where substantial subsidence and accumulation of siliceous and siliciclastic sediments have taken place during the Cenozoic.

The field forms a modest domal structure with predominant vertical stress as indicated by orientation of stylolites. Samples were recovered from a depth of $1950 \mathrm{~m}-2000 \mathrm{~m}$ sub-sea. Water depth is around 50 meters. Hydrocarbon migration from a Jurassic source rock has taken place since the Neogene.

All samples were collected from cores cut in the Ekofisk Formation of Early Paleocene (Danian) age. The chalk is primarily composed of calcitic biogenic mud representing nannofossil remains. It also contains sand-size microfossils, which may be filled with calcitic cement, and variable amounts of silt and microcrystalline quartz and clay (Fig. 2). The chalk samples fall in three porosity groups, each including three large samples and three smaller samples: high porosity $(45 \%-47 \%)$, medium porosity $(42 \%-43 \%)$ and low porosity $(32 \%$ 
Gram et al.

- 36\%) (Table 1). High and medium porosity samples have mudstone texture while low porosity samples have wacke/packstone texture (Fig. 2, Dunham 1962).

\section{EXPERIMENTAL PROCEDURE}

Mechanical testing was done on the nine large chalk samples. The samples represent the gas zone, but in order to simplify the experimental procedure, experiments were done with saline water or Isopar-L oil at room conditions $\left(25^{\circ} \mathrm{C}\right)$. The Isopar-L oil was free of dissolved gas, thus regarded as a dead oil, when modelling elastic parameters. Each large sample was accompanied by a neighbouring smaller sample, which was cleaned and dried and used for measuring elastic wave velocities in the dry state.

The samples were vertical cylinders with length to diameter ratios of $1.8-2.0$ for the large samples, and $1.2-2.5$ for the small samples (Table 1). Prior to testing, samples were CTscanned to ensure sample homogeneity. They were cleaned by the "cold flush, miscible liquids" cleaning technique to remove pore fluids including invaded filtrate from oil-based drilling mud (Hirasaki et al. 1990), presumably leaving the samples water-wet. All samples were dried at $110^{\circ} \mathrm{C}$, before Helium porosimetry. Carbonate content was measured on cleaned side trims (Table 1).

One set of large samples, comprising one sample from each porosity group, was saturated with Isopar-L oil. The six remaining large samples were saturated with $2.8 \%$ synthetic $\mathrm{NaCl}$ rich calcite equilibrated formation water and aged at $70^{\circ} \mathrm{C}$ for 2 days. The saturation was done by cold flush method and liquid permeability measured (Table 1). One set of the watersaturated samples was then treated according to the dilution-evaporation method (Springer et al. 2003) and injected with Isopar-L oil to obtain water-saturations of $10 \%$ for the high porosity sample, $17 \%$ for the medium-porosity sample, and $30 \%$ for the low-porosity sample. 
Gram et al.

These water-saturations correspond to in situ irreducible water-saturation as evaluated from well logs.

The uniaxial strain testing was done in a conventional high-pressure Hoek cell under axial displacement control with a feedback loop to the confining pressure. The steel pistons were fitted with stacked ultrasonic transducers providing P- and S-waves with frequencies in the order of $100 \mathrm{kHz}$. The small dry samples were tested in a smaller setup providing ultrasonic frequencies in the order of $200 \mathrm{kHz}$. Ultrasonic velocities were derived from sample length and first arrival of a signal. This procedure would yield group velocity, which in this case is close to the phase velocity of the dominating frequency. The tests were done with strain rate control of $0.3 \% / \mathrm{hr}-0.8 \% / \mathrm{hr}$ and with multiple creep phases. Deformation was monitored by precision balance weights measuring expelled and injected fluid mass, by two external Linear Voltage Displacement Transducers (LVDTs) and locally, by two sets of axial strain gauges and two sets of radial strain gauges. Strain gauges were not always continuously functional, and in four samples, when strain gauges failed, pressure on confining membrane was controlled by a fixed ratio of confining pressure and axial stress (Figs. 3-5).

For the set of samples with irreducible water-saturation, water-flooding with $1.5-2.2$ pore volumes of synthetic seawater at a rate of $2 \mathrm{ml} / \mathrm{h}$ caused no significant pore pressure build up (Figs. 3-5). Before initiating the water-flooding phase, each sample was left to creep in order to separate the two processes. The creep phase was maintained until the strain rate was less than $0.005 \% / \mathrm{hr}$. Water-saturation was calculated from strain and nature of expelled fluids, and the final saturation was compared to saturations determined after testing by distillation extraction (Dean and Stark 1920). 
Gram et al.

During the mechanical testing, ultrasonic compressional waves and two orthogonal shear waves (P- and S-waves) were collected with 2-3 MPa axial stress intervals, before and after creep phases and during water-flooding.

\section{DATA ANALYSIS}

During mechanical testing, the uniaxial deformation is measured as strain, $\varepsilon_{\mathrm{z}}$, defined as change in length $(\Delta L)$ relative to pre-test length $\left(L_{\text {init }}\right)$ :

$\varepsilon_{\mathrm{Z}}=\Delta L / L_{\text {init }}$,

but in order to compare the deformation of the different samples, strain is recalculated to resulting porosity $(\phi)$, assuming solid deformation to be insignificant and disregarding radial strain:

$\phi=\left(\phi_{\text {init }}-\varepsilon_{\mathrm{z}}\right) /\left(1-\varepsilon_{\mathrm{z}}\right)$,

where $\phi_{\text {init }}$ is the pre-test porosity.

Bulk density, $\rho_{\mathrm{b}}$, is calculated from pre-test density, $\rho_{\text {init }}$, fluid density, $\rho_{\mathrm{fl}}$, and strain:

$\rho_{\mathrm{b}}=\left(\rho_{\mathrm{init}}-\varepsilon_{\mathrm{z}} \rho_{\mathrm{fl}}\right) /\left(1-\varepsilon_{\mathrm{z}}\right)$,

where $\rho_{\mathrm{fl}}$ in the case of two pore fluids (water and oil) is calculated from water-saturation, $S_{\mathrm{w}}$, as

$\rho_{\mathrm{fl}}=\rho_{\mathrm{oil}}\left(1-S_{\mathrm{w}}\right)+\rho_{\mathrm{w}} S_{\mathrm{w}}$

and

$S_{\mathrm{w}}=\left(S_{\text {winit }} \phi_{\text {init }}+\Delta V_{\text {oil }} /\left(L_{\text {init }} A\right)-\varepsilon_{\mathrm{z}}\right) /\left(\phi_{\text {init }}-\varepsilon_{\mathrm{z}}\right)$,

where $S_{\text {winit }}$ is pre-test water-saturation, $\Delta V_{\text {oil }}$ is volume of produced oil, and $A$ is cross sectional area of sample. 
Gram et al.

Elastic bulk modulus of the sample, $K$, is calculated from $\mathrm{P}$-wave velocity, $V_{\mathrm{p}}$, $\mathrm{S}$-wave velocity, $V_{\mathrm{s}}$, and bulk density, $\rho_{\mathrm{b}}$ :

$K=\rho_{\mathrm{b}}\left(V_{\mathrm{p}}^{2}-4 V_{\mathrm{s}}^{2} / 3\right)$.

The bulk modulus of the pore fluid, $K_{\mathrm{fl}}$, was for the partially saturated samples modelled from calculated $S_{\mathrm{w}}$ and the assigned $K_{\mathrm{water}}$ and $K_{\mathrm{oil}}$, for respectively synthetic formation water together with the injected synthetic seawater and Isopar-L oil.

$K_{\mathrm{fl}}$ was derived as stiffest and softest bounds by respectively arithmetic average (Voigt) and harmonic average (Reuss) (citation in Mavko et al. 2009) and both resulting values used for all following calculations in order to assess possible range.

Average according to Voigt:

$K_{\mathrm{fl}}=S_{\mathrm{w}} K_{\mathrm{water}}+\left(1-S_{\mathrm{w}}\right) K_{\mathrm{oil}}$.

Average according to Reuss:

$\frac{1}{K_{\mathrm{fl}}}=\frac{S_{\mathrm{w}}}{K_{\mathrm{water}}}+\frac{\left(1-S_{\mathrm{w})}\right.}{K_{\mathrm{oil}}}$

(10)

The solid bulk modulus $K_{\mathrm{m}}$, was modelled from carbonate content (Table 1) and the observation that calcite is the dominating carbonate mineral, whereas quartz is dominating among non-carbonate minerals (Fabricius et al. 2008). Voigt- and Reuss bounds were again applied, this time for allowing max- and minimum $K_{\mathrm{m}}$ estimation and assessment of uncertainty. Elastic constants for minerals and fluids are listed in Table 2.

Given $\phi, K, K_{\mathrm{fl}}$ and $K_{\mathrm{m}}$ (where $K_{\mathrm{fl}}$ and $K_{\mathrm{m}}$ contains a min-max range), the elastic bulk modulus of the dry porous rock frame, $K_{\text {dry }}$, can be modelled by Gassmann (1951) fluid substitution, i.e. 
Gram et al.

$\frac{K_{\mathrm{dry}}}{K_{\mathrm{m}}-K_{\mathrm{dry}}}=\frac{K}{K_{\mathrm{m}}-K}-\frac{K_{\mathrm{fl}}}{\phi\left(K_{\mathrm{m}}-K_{\mathrm{fl}}\right)}$

(11)

Gassmann's equation applies for ideal, pseudo static conditions, where $K_{\text {dry }}$ refers to a fully drained state with constant pore pressure, and $K$ refers to a fully undrained state with constant mass although variable density.

Bulk modulus for the two states may be derived from elastic wave velocity, provided the elastic waves are in the low frequency range as defined by Biot (1956). These conditions imply that for $K_{\mathrm{dry}}$, the saturating air has constant pressure, and that in the undrained fluid saturated state the pore fluid moves in unison with the enclosing solids. The pore size in chalks is so small that in the water-saturated case this precondition holds even for ultrasonic frequency up to $1 \mathrm{MHz}$ (Fabricius et al. 2010). Accordingly, bulk modulus for dry samples, and fluid substituted monitoring data show good agreement (Fig. 6).

Subsequently, Biot's coefficient, $\alpha$ was determined given the modelled $K_{\text {dry }}$ and $K_{\mathrm{m}}$ (equation

2). The resulting range for $\alpha$, is expressed as follows; maximum $\alpha$ is obtained by Voigt mixture for fluids and minerals, whereas minimum values for $\alpha$ occur, when Reuss averages are used for mixing fluids and minerals. The reason is that for a given bulk modulus, few contacts (higher $\alpha$ ) are needed for stiff minerals and fluids, whereas a good bonding (low $\alpha$ ) is required for soft minerals and fluids.

For assessment of the visibility of water-flooding from 4D seismic, Poisson's ratio, $v$, was calculated from ultrasonic velocities as:

$v=\frac{V_{p}^{2}-2 V_{s}^{2}}{2\left(V_{p}^{2}-V_{s}^{2}\right)}$ 
Gram et al.

and acoustic impedance, $Z$, was calculated as:

$Z=\rho_{b} V_{p}$

(13)

\section{RESULTS}

Consolidation curves were constructed from axial load. Strain is expressed as decline in porosity in order to compare consolidation curves of samples with different initial porosity.

The two methods of measuring strain (balance weights and LVDT) gave values differing less than 0.5 p.u. (porosity units) in six tests, and differing less than 1.5 p.u. in porosity after unloading in the remaining three tests (Figs. 7-12). There is no clear systematic difference in strain measured by the two methods and the same general picture arises. The maximal stress level during testing is $50 \mathrm{MPa}$ so that strain of solids is less than $0.05 \%$. The samples in the high porosity group are similar with respect to porosity and carbonate content (initial porosity $45 \%-47 \%$, carbonate $90 \%-95 \%$, Table 1). Samples from the medium porosity groups have similar initial porosity (42\%), although they vary with respect to carbonate content ( $88 \%$ for the oil-saturated and water-flooded samples, and $96 \%$ for the water-saturated sample). For the samples in the low porosity group, the carbonate content of the watersaturated sample is high (89\%), whereas the two remaining samples have similar but relatively low carbonate content $(74 \%-76 \%)$. These three samples vary 4 p.u. with respect to initial porosity $(32 \%-36 \%$, Table 1$)$. Ultrasonic wave velocities were successfully recorded in most intervals and the corresponding Biot's coefficient calculated (Figs. 7-12).

Strength and elasticity

This article is protected by copyright. All rights reserved. 
Gram et al.

An "elastic phase", a "transitional phase", and an "elastoplastic phase" can be defined for most consolidation curves, and in some cases a "strain hardening phase" was also recorded. The curves confirm the expectation that for similar porosity, oil-saturated chalk is stronger than water-saturated chalk (Figs. 7-12). A compressional modulus (I) expresses the slope in the "elastic phase" and a compressional modulus (III) expresses the slope in the "elastoplastic phase". An additional compressional modulus represents unloading. With respect to order of size, compressional modulus from loading (I) and compressional modulus as measured during unloading form a general decreasing trend with increasing porosity, but compressional modulus from unloading is higher than from loading (Table 3, Fig. 13). A relatively high carbonate content is probably the reason for the relatively high compressional modulus for the water saturated sample with medium porosity. Compressional modulus (III) from the "elastoplastic phase" is generally one order of magnitude lower than in the other phases (Table 3, Fig. 13). Compressional modulus as modelled from bulk density and ultrasonic velocity is higher than the values measured from static data in phase (I) and (III), whereas no clear pattern is seen in the unloading phase (Table 3). Dynamic elasticity as expressed in Biot's coefficient follows a general pattern (Figs. 7-12). In the initial "elastic phase" where porosity declines at a slow rate, Biot's coefficient decreases at a relatively high rate for oilsaturated samples and samples with irreducible water-saturation. For the water-saturated samples the decline is smaller and even absent for the high porosity chalk. At the first yield point where the "transitional phase" begins, Biot's coefficient does not change significantly for the water-saturated low porosity chalk, but increases for the two other water-saturated chalk samples and for all oil-saturated chalk samples as a sign of decreasing elastic modulus. After second yield point, Biot's coefficient is close to stable in the "elastoplastic phase" before decreasing at a moderate rate during the "strain hardening phase". 
Gram et al.

\section{Creep and water flooding}

During intervals of creep, porosity decreases up to two p.u., but upon resumed loading porosity remains constant until the extrapolated original virgin loading curve is reached again. For samples at irreducible water-saturation a marked decrease in porosity and Biot's coefficient was found during creep before water-flooding, and also at creep phases subsequent to water-flooding. During water-flooding, porosity remains stable in all cases, whereas Biot's coefficient tends to increase for the high porosity and medium porosity chalk (Figs. 8, 10, 12).

\section{Poisson's ratio and acoustic impedance}

With respect to acoustic impedance and Poisson's ratio, both properties increase during loading. For the high porosity and medium porosity chalk, values are higher in the watersaturated state than in the oil-saturated state irrespective of state of compaction, and values for the flooded sample shifts from being close to the oil-saturated sample to being close to the water-saturated sample (Fig. 8 and 10). For low porosity chalk, the calcite-rich watersaturated sample falls at a distinct trend from the less calcite rich oil-saturated and waterflooded samples (Fig. 12). The Poisson's ratio and acoustic impedance effect of porosity and fluid saturation is summarised in Fig. 14.

\section{DISCUSSION}

Consolidation curves obtained from the tests can all be split into phases in accordance with the description in Kågeson-Loe et al. (1993), but monitoring with ultrasonic velocities allows modelling bounds for Biot's coefficient during testing, and this facilitates interpretation of 
Gram et al.

consequent textural changes. In the "elastic phase" the porosity decreases as a close-to-linear function of stress and it is possible to derive an elastic Compressional Modulus (I) from the stress-strain slope, and we find that the modulus increases with falling porosity, and that it in two cases is higher in the oil-saturated than the water-saturated case (Table 3, Fig. 13).

Nevertheless, for most samples Biot's coefficient decreases markedly in this phase. This result indicates that the chalk does not act linearly elastic in the "elastic phase", that there is a significant plastic component and that chalk largely attains isotropy in this phase (Hickman 2004). For this reason, the slope is too steep, and the elastic modulus becomes too low. This effect contributes to explaining the observation by Azeemuddin et al. (2001) that Biot's coefficient modelled from static data is higher than calculated from ultrasonic data. The decreasing Biot's coefficient in the "elastic phase" indicates that the grain contacts widen, and the chalk consequently stiffens. 
Gram et al.

\section{Yielding}

In the "transitional phase" between the two yield points, porosity declines at an increasing rate and at the same time Biot's coefficient increases. For the samples fully saturated with water, yield requires less stress for samples with high Biot's coefficient than for samples with low Biot's coefficient at the end of the "elastic phase". In accordance with the interpretation of Kågeson-Loe et al. (1993) this would mean that contact cement gradually breaks, facilitating porosity reduction by grain sliding. For each porosity group, oil-saturated samples and samples with irreducible water-saturation are relatively strong, and yield occurs at higher stress than for fully water-saturated samples (Figs. 7-12). This would indicate that the difference in kinematic viscosity among the movable fluids causes the water-saturated sample to be weaker, due to the lower kinematic viscosity of water (Table 2, Andreassen and Fabricius 2010). For fully water-saturated samples, an additional effect can be reduced friction in water-saturated samples caused by electrical repulsion among particles, which arises when the chalk is saturated with an electrolyte (Megawati et al. 2013, Meireles et al. 2020). Capillary effects as proposed by Schroeder et al. (1998) will have a stiffening effect at irreducible water-saturation, and also lower surface energy of wetted calcite as compared to non-wetted calcite (Røyne et al. 2011) could be a factor in delaying first yield point of oilsaturated chalk (Voake et al. 2019). Chemical dissolution as proposed by Madland et al. (2006) is hardly relevant here due to the relatively rapid tests, and reactivation of fault planes (Christensen et al. 2003) is also hardly relevant for the studied massive samples. 
Gram et al.

\section{After yield}

In the "elastoplastic phase", Biot's coefficient in most cases remains constant while porosity decreases. This indicates elastic strain on the frictional packing of particles, so that the resulting virgin slope (Compressional Modulus III, Table 3, Fig. 13) reflects the low elastic modulus for the collapsed material. During creep phases, plastic deformation takes place, porosity decreases, the particles rearrange to closer packing, and Biot's coefficient decreases. During the following "strain hardening phase" which is most pronounced in the oil-saturated high porosity chalk, porosity reduces at a slightly lower rate, while the increased stress needed in order to make particles slide past each other is reflected in decreasing Biot's coefficient. Strain hardening of oil-saturated and water-flooded samples seem to take place at comparable stress for a given porosity.

\section{Water flooding}

During water-flooding after a period of creep in the "transitional phase" of samples with irreducible water-saturation, Biot's coefficient tends to increase, except for the low porosity samples, while porosity is stable (Figs. $8,10,12$ ). The synthetic formation water and the injected synthetic seawater are both $\mathrm{NaCl}$ dominated and have similar salinity $(2.8 \%)$, so electrical repulsion among particles should be similar. This would leave the possibility that the flooding locally releases capillary pressure according to the mechanism proposed by Schroeder et al. (1998). In relation to 4D seismic, water-flooding will increase fluid density and hence have a density increasing effect and a similar increasing effect on acoustic impedance (Figs. 8, 10, 12, 14). This shows that although an increase in Biot's coefficient would have a diminishing effect on elastic wave velocities and hence a decreasing effect on 
Gram et al.

acoustic impedance, the effect is relatively small. The overall effect of water-flooding is a significant increase in acoustic impedance as well as in Poisson's ratio. This allows 4D seismic to resolve water-flooded zones in a chalk reservoir, especially where data have AVO information and a high signal-to-noise ratio.

\section{CONCLUSIONS}

During uniaxial strain testing of chalk from a North Sea field, with samples in the porosity range $32 \%-47 \%$, yield strength and elastic bulk modulus were found to be primarily controlled by porosity. For a given porosity, samples saturated with oil were found to have higher yield strength than samples saturated with water. Samples saturated with water at irreducible saturation and the remaining pore space filled with oil were found to have yield strength similar to oil-saturated samples. This would indicate that the difference in strength may be linked to the higher kinematic viscosity of oil than of water. An effect of supposed change in wettability is thus not supported by these findings.

Irrespective of pore fluid, samples compact according to the classical four phases: an "elastic phase", a "transitional phase", an "elastoplastic phase", and a "strain hardening phase", although these terms may not all be fully descriptive of the process.

The "elastic phase" was found not to be linearly elastic because Biot's coefficient declines markedly during this deformation. This makes the stress-strain slope unsuitable for prediction of elastic modulus. The plastic component in the deformation may be closure of micro-cracks and broadening contacts among particles. 
Gram et al.

For oil-saturated or water-saturated chalk, the "transitional phase" of yield was characterized by decreasing porosity but increasing Biot's coefficient as a reflection of breaking bonds among particles.

Water-flooding causes Biot's coefficient to increase for the already water wet chalk at irreducible water-saturation, possibly due to capillary pressure release at particle contacts, and in the studied water-wet chalk no chemically related water-weakening is indicated.

In the "elastoplastic phase" deformation along the virgin curve seems to be elastic with only small accompanying change in Biot's coefficient. By contrast, during the phases of creep, both porosity and Biot's coefficient decreases as a reflection of plastic deformation involving closer packing of particles.

In the "strain hardening phase" both porosity and Biot's coefficient decrease as a reflection of shifting of particles during elastoplastic deformation.

Irrespective of state of compaction, chalk with initial porosity above $40 \%$ has distinctly higher acoustic impedance and Poisson's ratio when water-saturated or water-flooded, than when oil-saturated or with irreducible water-saturation prior to flooding. This would make feasible 4D seismic monitoring of water-flooding.

\section{ACKNOWLEDGEMENTS}

We thank Maersk Oil and the DUC Partners, A.P. Møller-Mærsk AS, Shell Olie- og Gasudvinding Danmark B.V. (Holland), Chevron Denmark Inc. and the Danish North Sea 
Gram et al.

Fund for permission to publish this material. The opinions expressed in the paper are those of the authors and do not necessarily represent those of Maersk Oil. Leonardo Meireles and Tobias Orlander are thanked for critically reading this manuscript. Morten Hjuler recorded backscatter electron micrographs. Associate editor Dave Dewhurst and two anonymous reviewers are thanked for relevant and constructive comments. 
Gram et al.

\section{FIGURE CAPTIONS}

Figure 1. Generic loading curve (blue line) illustrating the relationship between applied stress and resulting strain. Black dashed line depicts a virgin compaction development if no creep phases are conducted. First yield point is determined as first deviation from a linear relation between applied stress and strain in the "elastic phase", and second yield point is defined from the beginning of a linear relation between stress and strain in the "elastoplastic phase", followed by a phase of "strain hardening” (phases based on Kågeson-Loe et al. 1993). Axial strain progress during creep where stress is held constant, but at resumed loading the strain halts until the virgin compaction curve is reached.

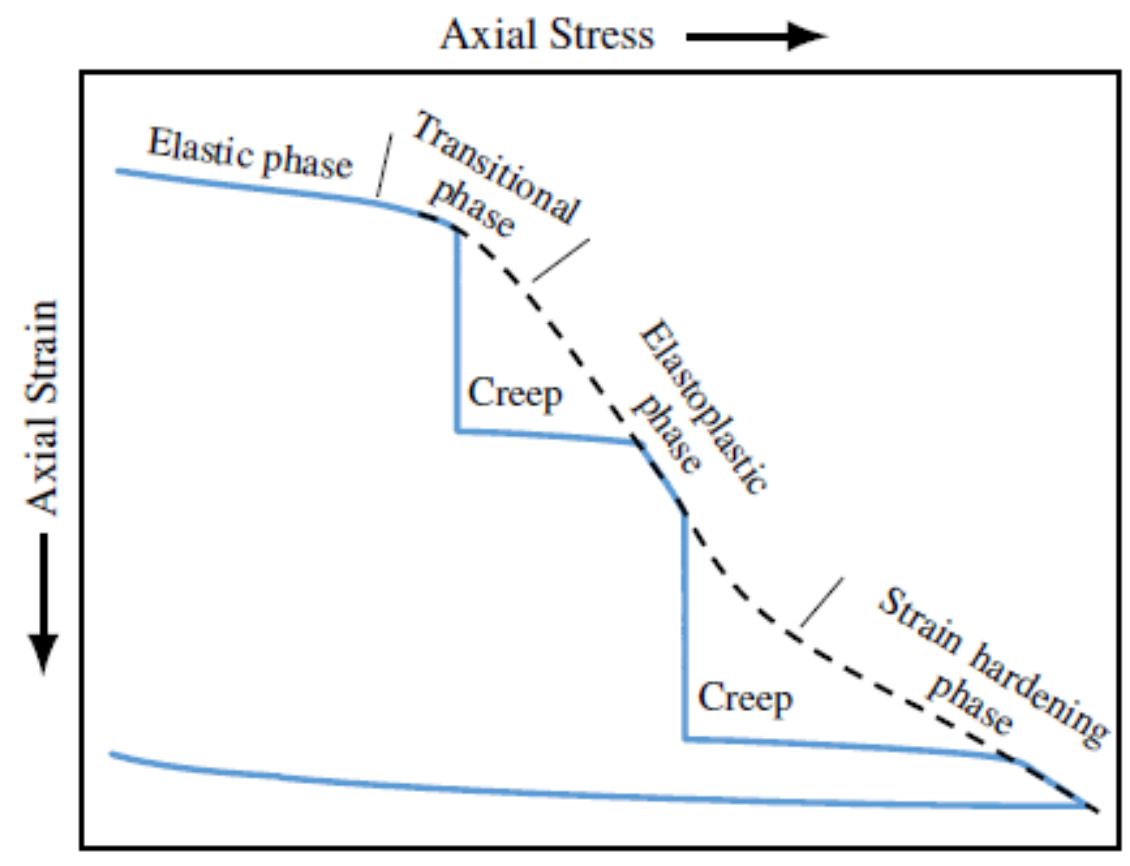


Gram et al.

Figure 2. Backscatter electron micrographs of epoxy impregnated polished chalk samples from the Ekofisk Formation of Danian age from the same field as the tested samples. Each sample is represented by an overview image to illustrate the texture and a close-up image to illustrate the pore structure. (a) and (b) high porosity (47\%) chalk with $85 \%$ calcite, (c) and (d) medium porosity (40\%) chalk with $95 \%$ calcite, (e) and (f) low porosity (34\%) chalk with $88 \%$ calcite (lightest grey). The non-carbonate fraction (medium grey) is mainly microquartz, probably precipitated in pore space.
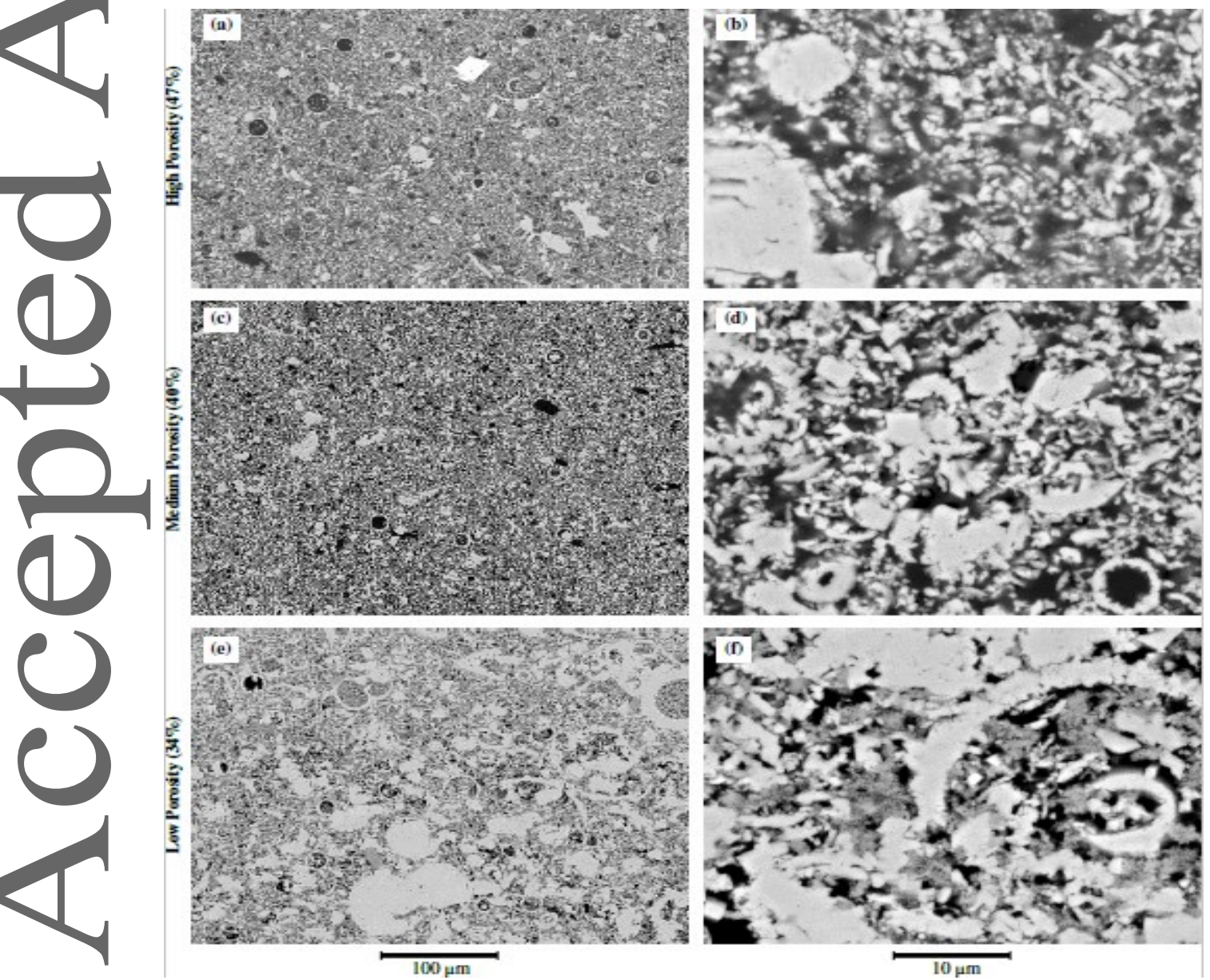

This article is protected by copyright. All rights reserved. 
Gram et al.

Figure 3. Development of stress, pore pressure and radial strain throughout tests on high porosity chalk samples. The sample with irreducible water-saturation was only monitored for radial strain by one radial strain gauge throughout the test.
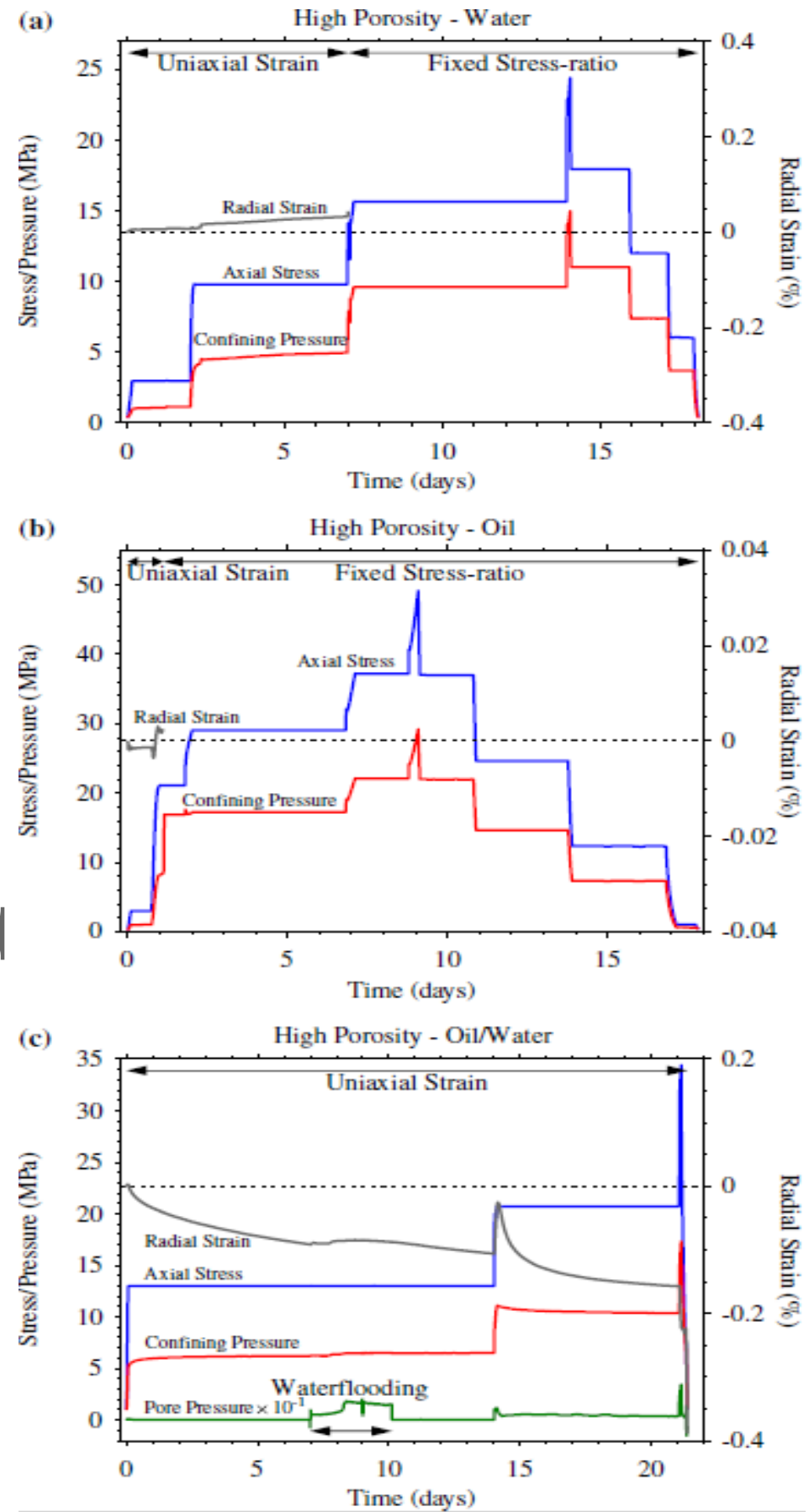

This article is protected by copyright. All rights reserved. 
Gram et al.

Figure 4. Development of stress, pore pressure and radial strain throughout tests on medium porosity chalk samples. The water-saturated sample was only monitored for radial strain by one radial strain gauge throughout the test.
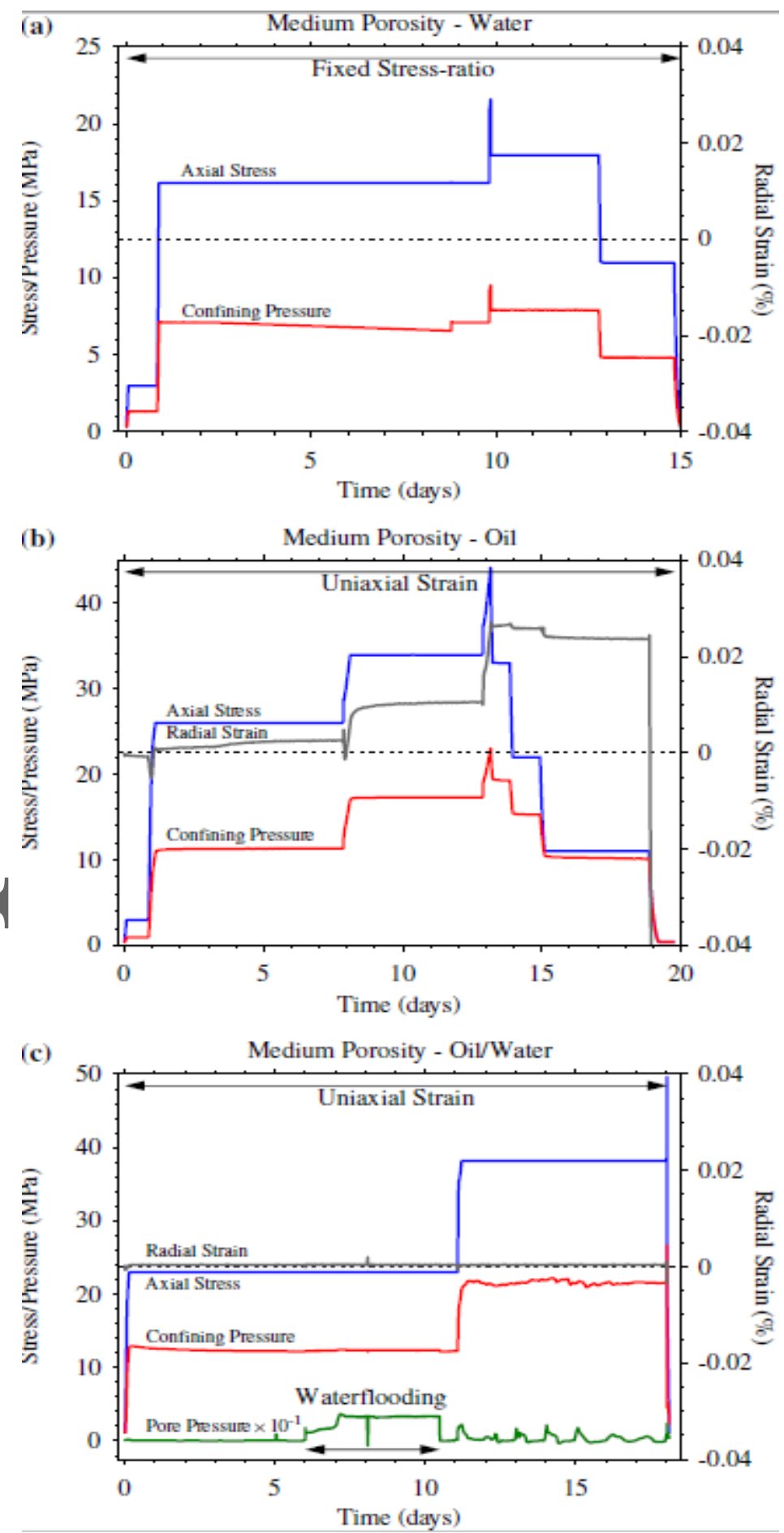

This article is protected by copyright. All rights reserved. 
Gram et al.

Figure 5. Development of stress, pore pressure and radial strain throughout tests on low porosity chalk samples. The testing of the oil-saturated sample did only maintain radial control by one radial strain gauge after the first creep phase $(2.5 \mathrm{MPa})$.
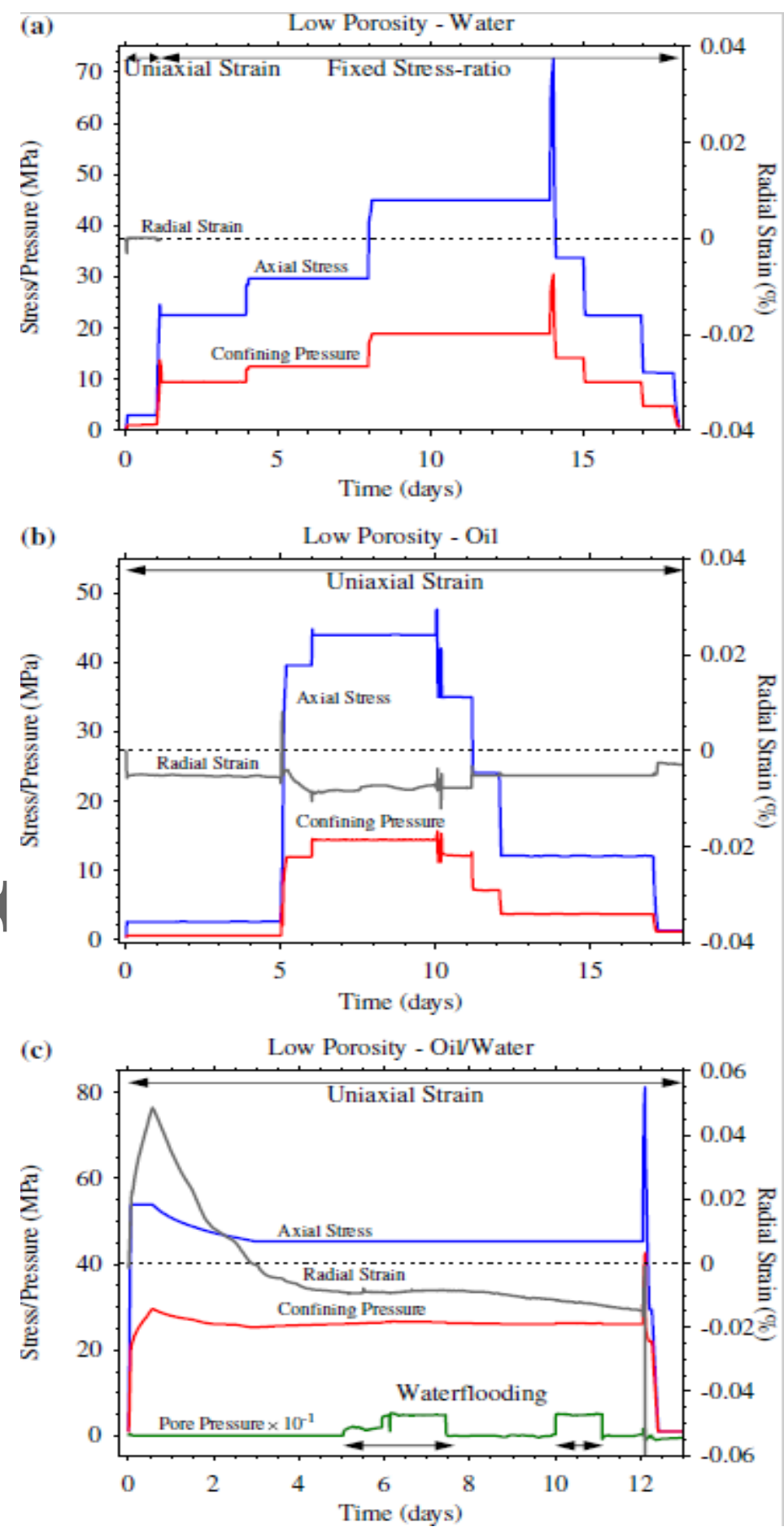

This article is protected by copyright. All rights reserved. 
Gram et al.

Figure 6. (a) Bulk modulus as calculated from elastic wave velocity and bulk density (equations 5-8). Bulk modulus increases with decreasing porosity. For a given porosity, bulk modulus varies according to pore fluid, so that dry samples have lowest bulk modulus, oil (Isopar-L) saturated samples have intermediate bulk modulus, and samples saturated with synthetic formation water have the highest bulk modulus. Flooding with synthetic seawater causes samples to shift from oil-saturated trend to water-saturated trend. (b) The same data transformed via Gassmann fluid substitution (equation 11). The fluid saturated samples consequently plot close to the dry samples.
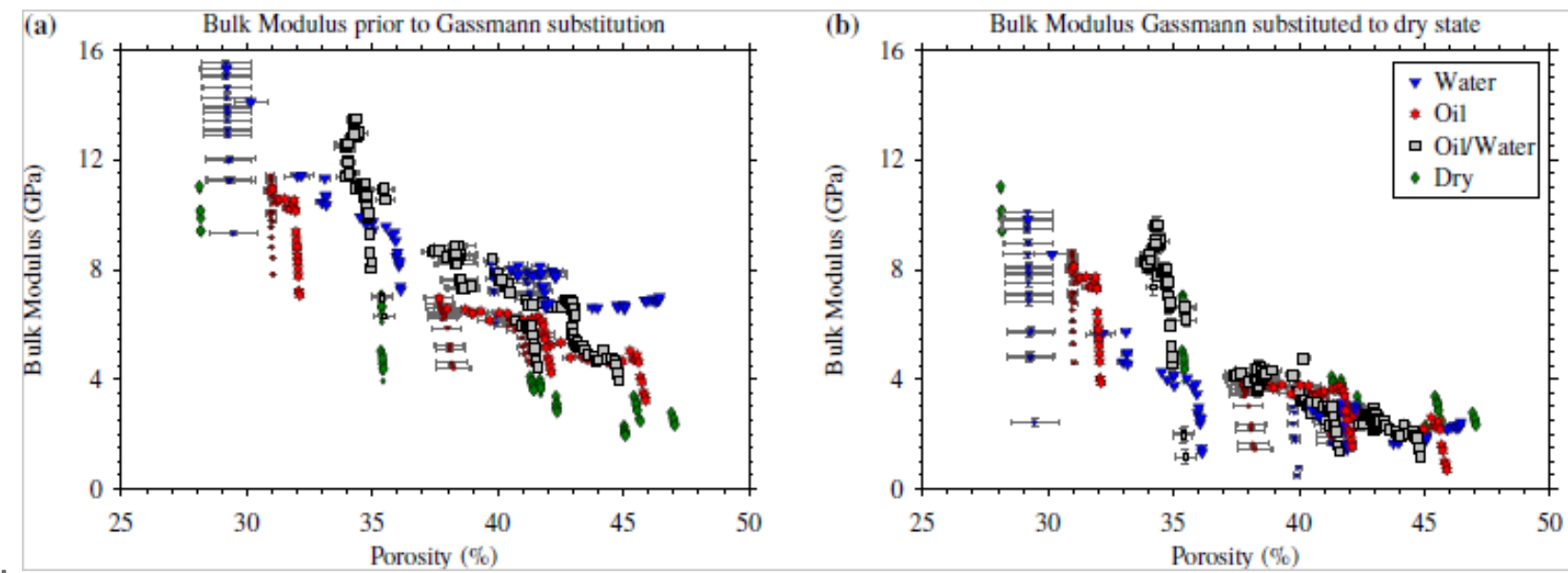

Figure 7. Data representing uniaxial strain tests for high porosity chalk samples. Difference between strain calculated from mass of expelled fluids and from LVDTs are reflected in error bars. Shading: I the traditionally termed "elastic phase", II the "transitional phase", III the "elastoplastic phase", IV the "strain hardening phase" (refer Fig. 1). One sample was saturated with synthetic formation water (a, c, e), one sample with Isopar-L oil (b, d, f). In all plots, the symbols indicate points where ultrasonic data were measured. Large symbols represent loading, whereas small symbols represent unloading. Data for associated dry samples are shown for reference (green symbols). (a) and (b) Results from ultrasonic monitoring of P- and S-waves. (c) and (d) Consolidation curves represented in terms of axial stress and porosity. Intervals fulfilling boundary conditions of uniaxial strain, and/or intervals 
Gram et al.

run with applied fixed stress-ratio are indicated by arrows. (e) and (f) Biot's coefficient as modelled from ultrasonic velocities and bulk density calculated from initial density and mass of expelled (and injected) fluids. Upper and lower bounds for Biot's coefficient are shown by error bar.
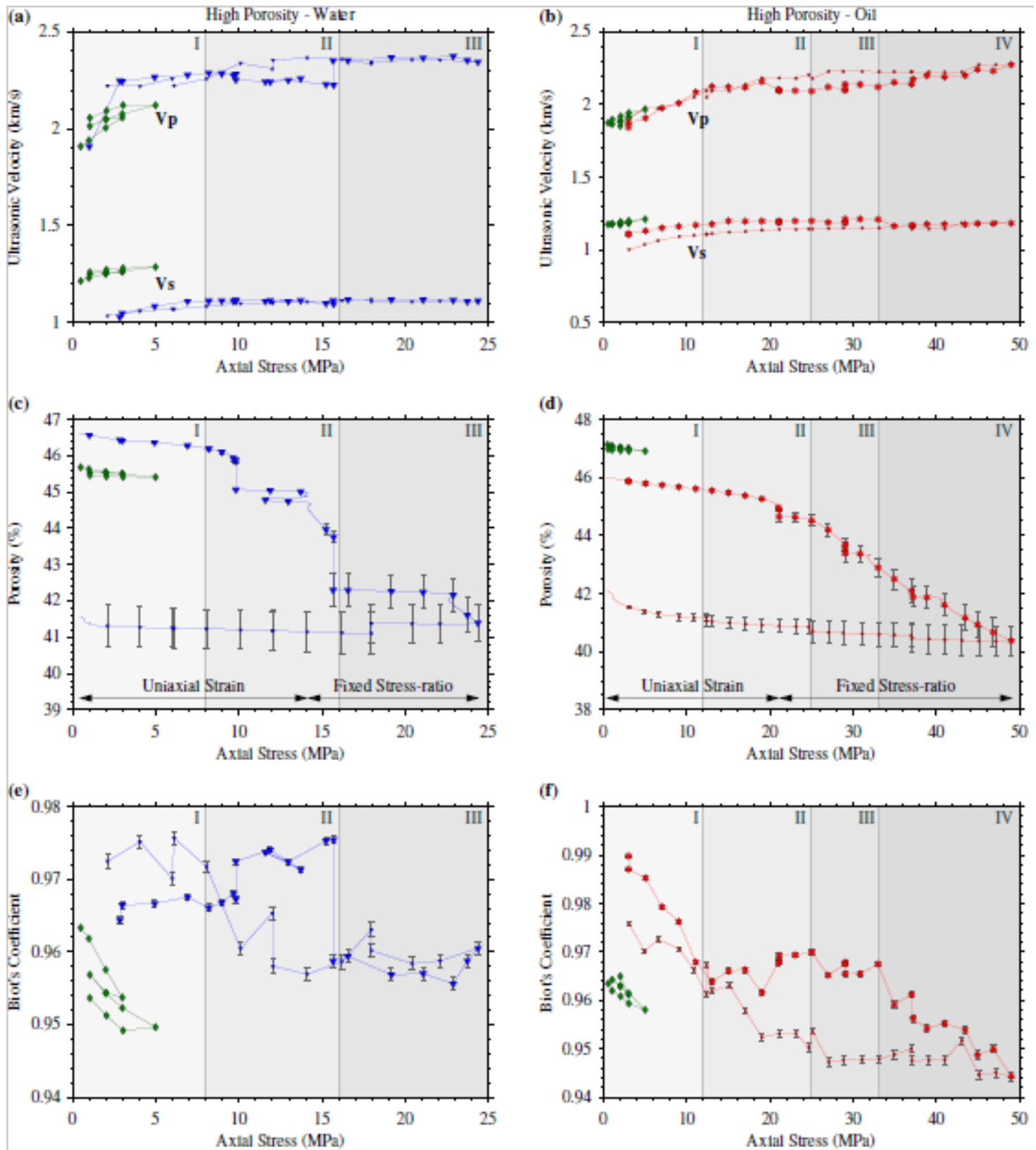

This article is protected by copyright. All rights reserved. 
Gram et al.

Figure 8. (a, c, e) Data representing the uniaxial strain tests for a high porosity chalk sample. Refer to Fig. 7 for general explanation. The sample was saturated with synthetic formation water and Isopar-L oil at irreducible water-saturation, and in the "transitional phase" flooded with $1.5-2$ pore volumes of synthetic seawater (arrow). (b) cross-plot of Acoustic impedance and Poisson's ratio shows effect of consolidation, pore fluid and water-flooding. (d) Porosity during water-flooding. (f) Biot's coefficient during water-flooding. The error bars indicate upper and lower bounds for the model. Dean Stark analyses of samples after testing found water-saturation of $73 \%$. The final water-saturation measured from balance weights is $5 \%-15 \%$ higher than saturations from the Dean Stark analysis.
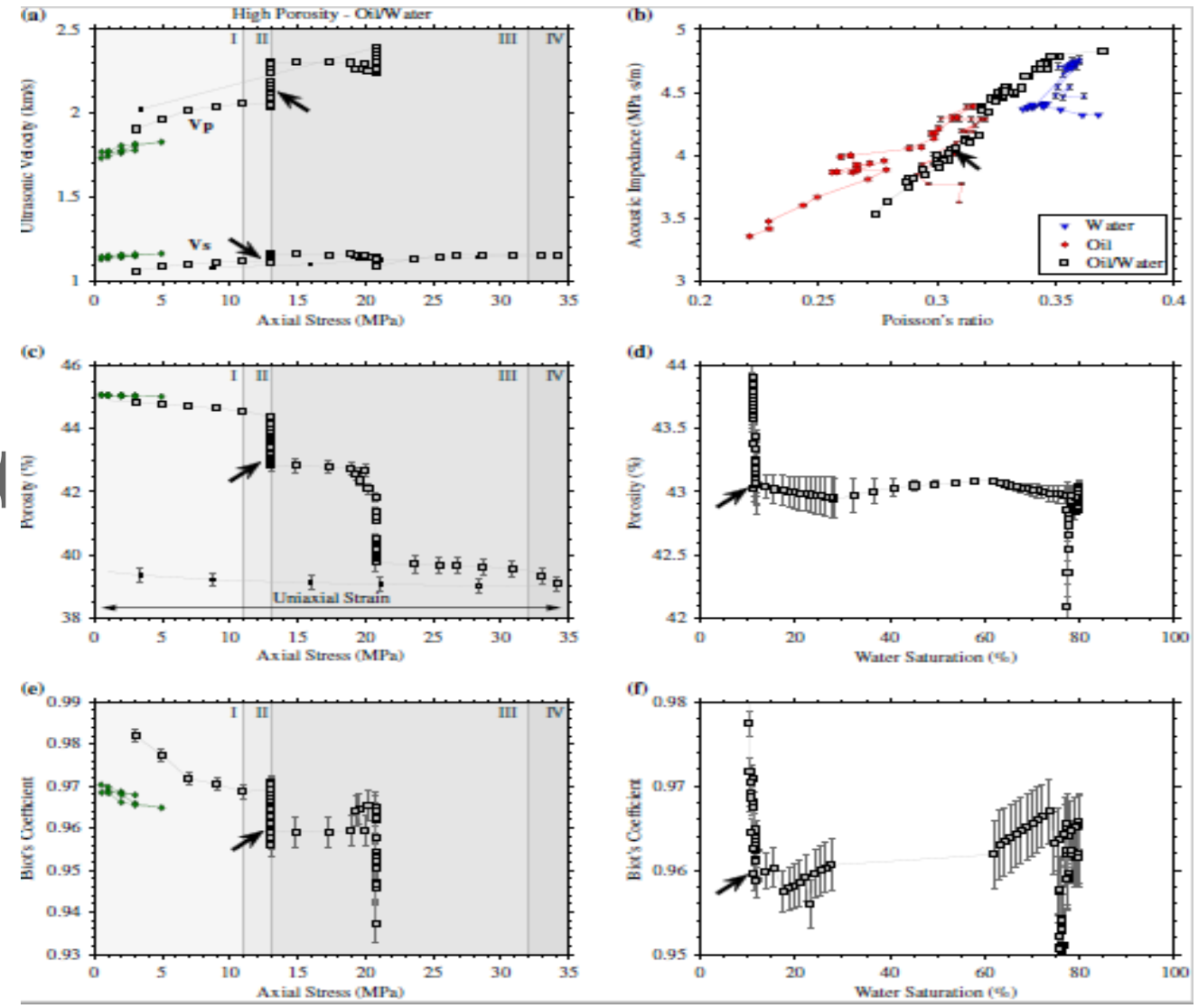

This article is protected by copyright. All rights reserved. 
Figure 9. Data representing uniaxial strain tests for medium porosity chalk samples. Refer to Fig. 7 for explanation.
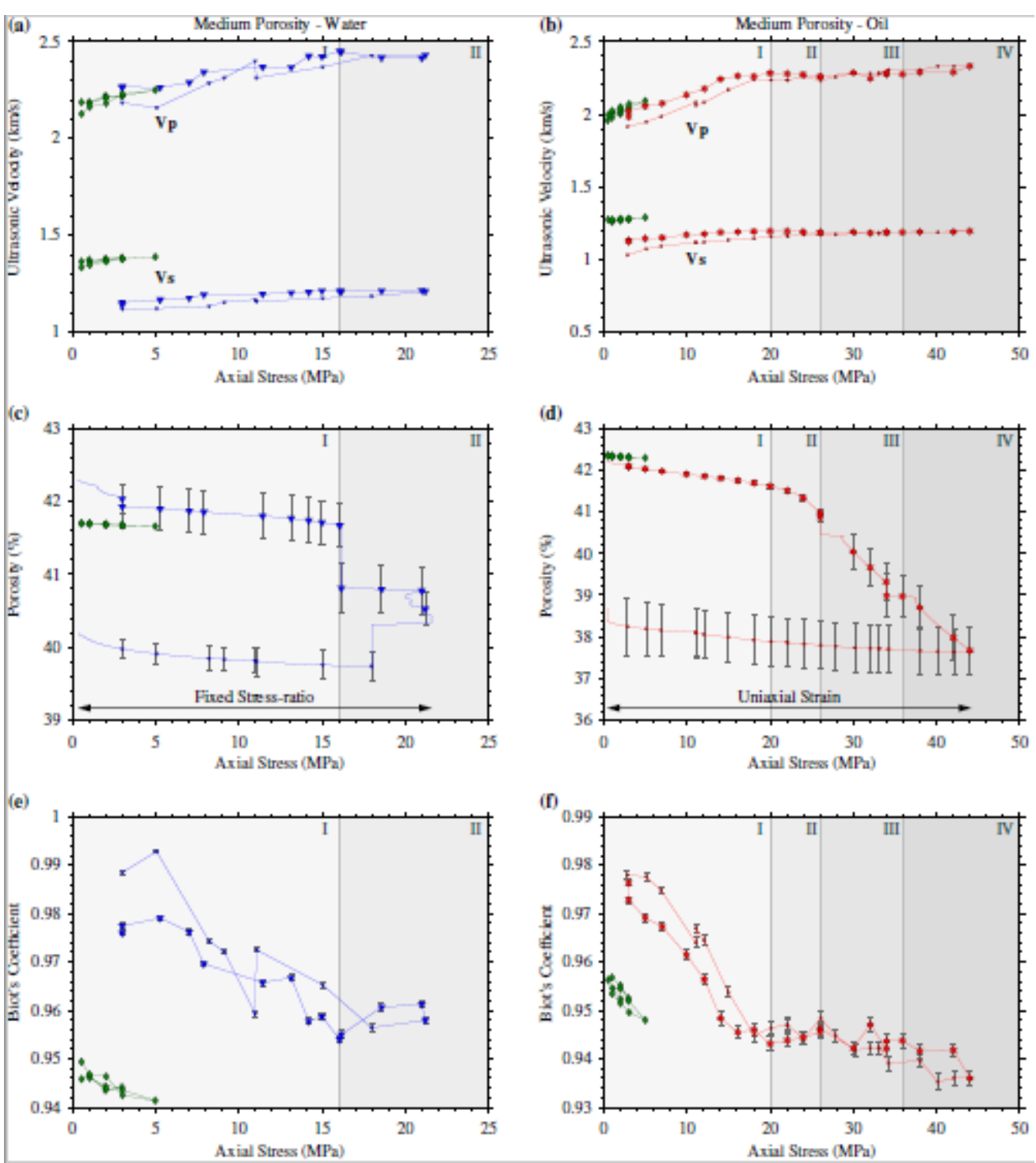

Figure 10. (a, c, e) Data representing the uniaxial strain tests for a medium porosity chalk sample. Refer to Fig. 7 for general explanation. The sample was saturated with synthetic formation water and Isopar-L oil at irreducible water-saturation, and after the "transitional phase" flooded with 1.5 - 2 pore volumes of synthetic seawater (arrow). (b) cross-plot of Acoustic impedance and Poisson's ratio shows effect of consolidation, pore fluid and waterflooding. (d) Porosity during water-flooding. (f) Biot's coefficient during water flooding. The error bars indicate upper and lower bounds for the model. Dean Stark analyses of samples 
Gram et al.

after testing found water-saturation of $66 \%$. The final water-saturation measured from balance weights is $5 \%-15 \%$ higher than saturations from the Dean Stark analysis.
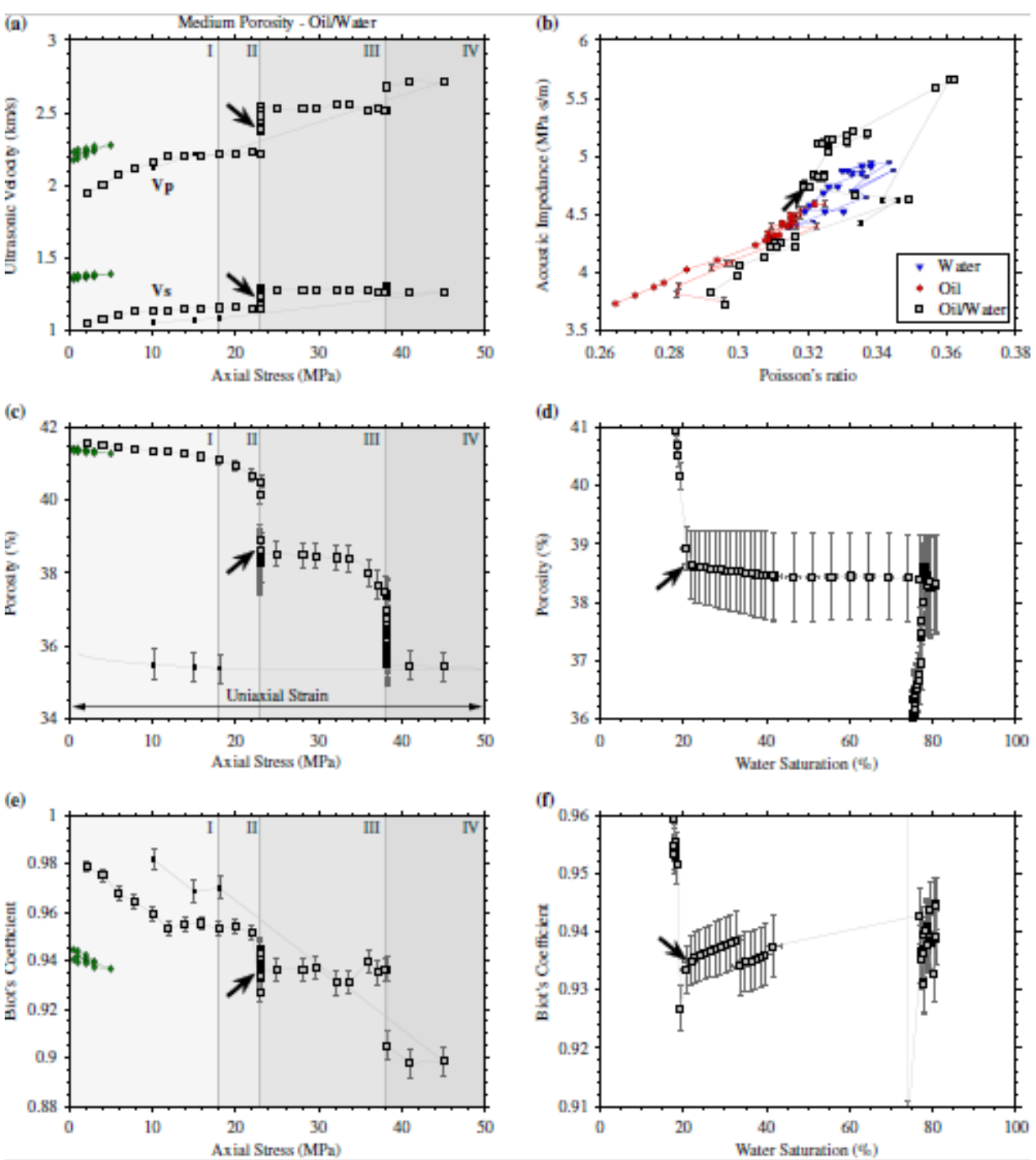

This article is protected by copyright. All rights reserved. 
Gram et al.

Figure 11. Data representing uniaxial strain tests for low porosity chalk samples. Refer to Fig.

7 for explanation.
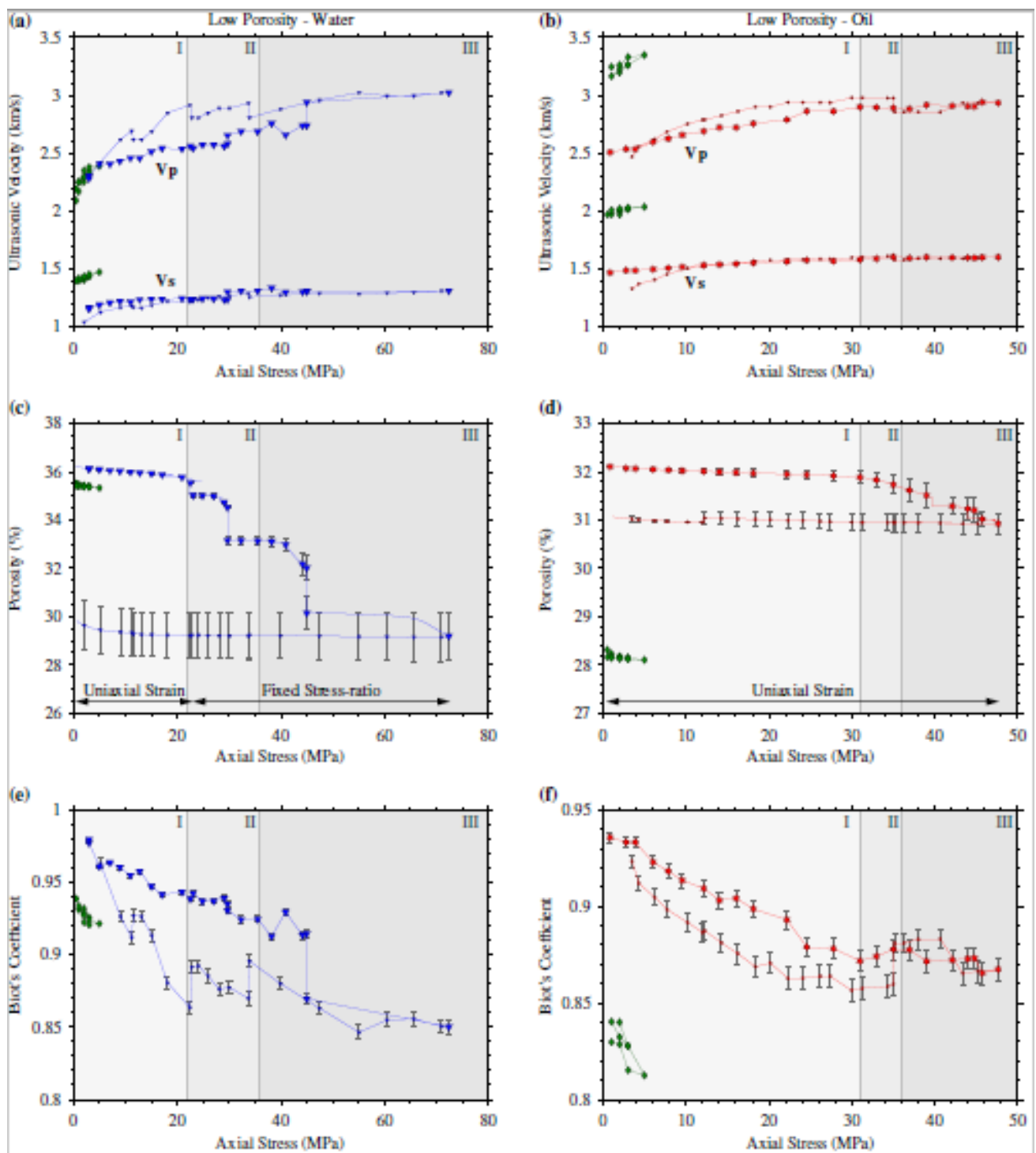
Gram et al.

Figure 12. (a, c, e) Data representing the uniaxial strain tests for a low porosity chalk sample. Refer to Fig. 7 for general explanation. The sample was saturated with synthetic formation water and Isopar-L oil at irreducible water-saturation, and in the "transitional phase" flooded with $1.5-2$ pore volumes of synthetic seawater (arrow). (b) cross-plot of Acoustic impedance and Poisson's ratio shows effect of consolidation, pore fluid and water-flooding. (d) Porosity during water-flooding. (f) Biot's coefficient during water-flooding. The error bars indicate upper and lower bounds for the model. Dean Stark analyses of samples after testing found water-saturation of $63 \%$. The final water-saturation measured from balance weights is $5 \%-15 \%$ higher than saturations from the Dean Stark analysis.
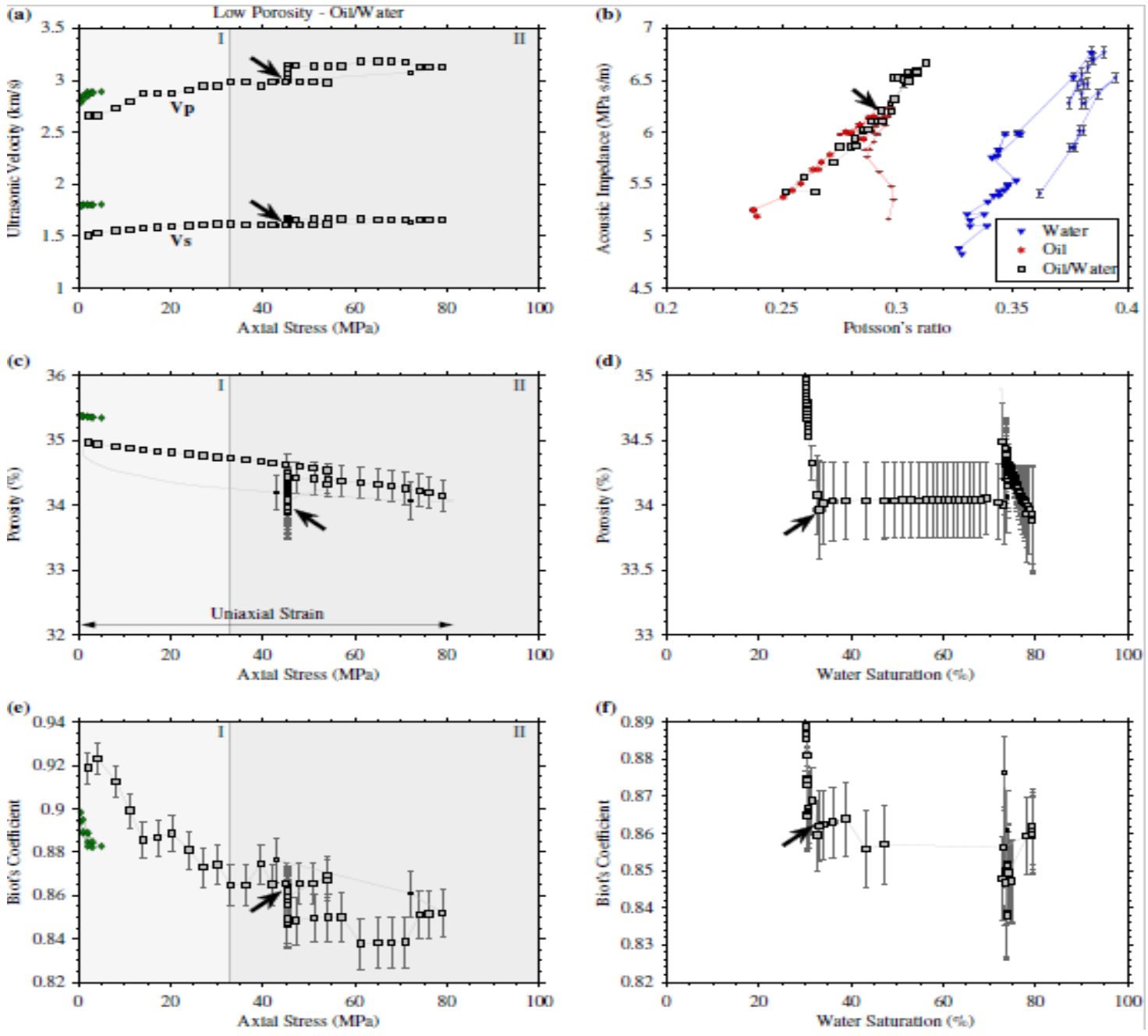

This article is protected by copyright. All rights reserved. 
Gram et al.

Figure 13. Compressional modulus versus porosity for three phases of the experiment. The compressional modulus (I) defined from the stress strain curve in the initial, "elastic phase" is marked be a black circular background. Compressional modulus (III) after pore collapse is markedly lower, but for a given porosity relatively high for oil saturated samples.

Compressional modulus from the unloading phase is higher than from the initial phase.

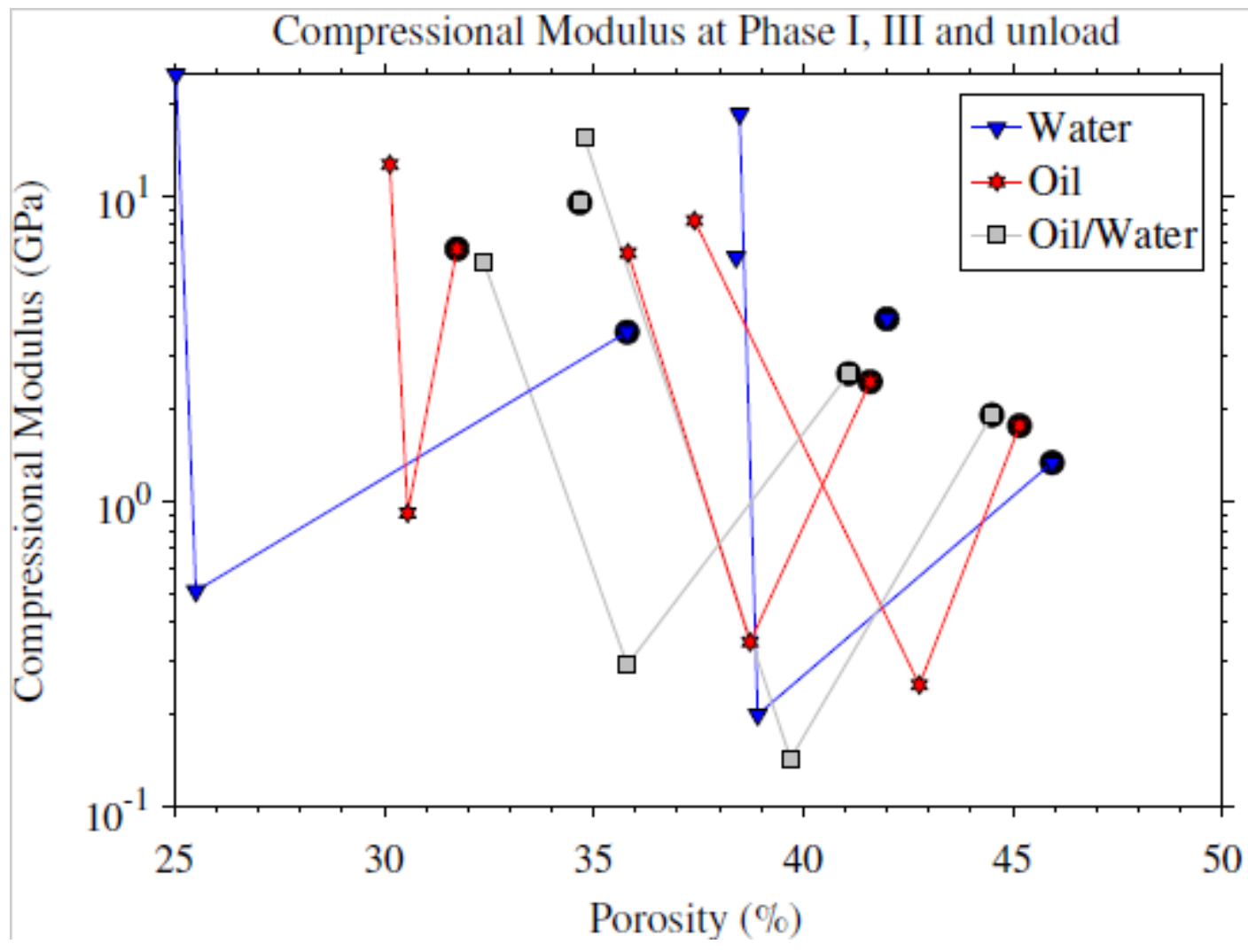


Gram et al.

Figure 14. Cross plot of acoustic impedance and Poisson's ratio for all data. (a) The colour coding show water-saturation ranging from pure water (blue) to pure oil (red). (b) The colour coding ranges from Biot's coefficient 0.8 (blue) to 1.0 (red).
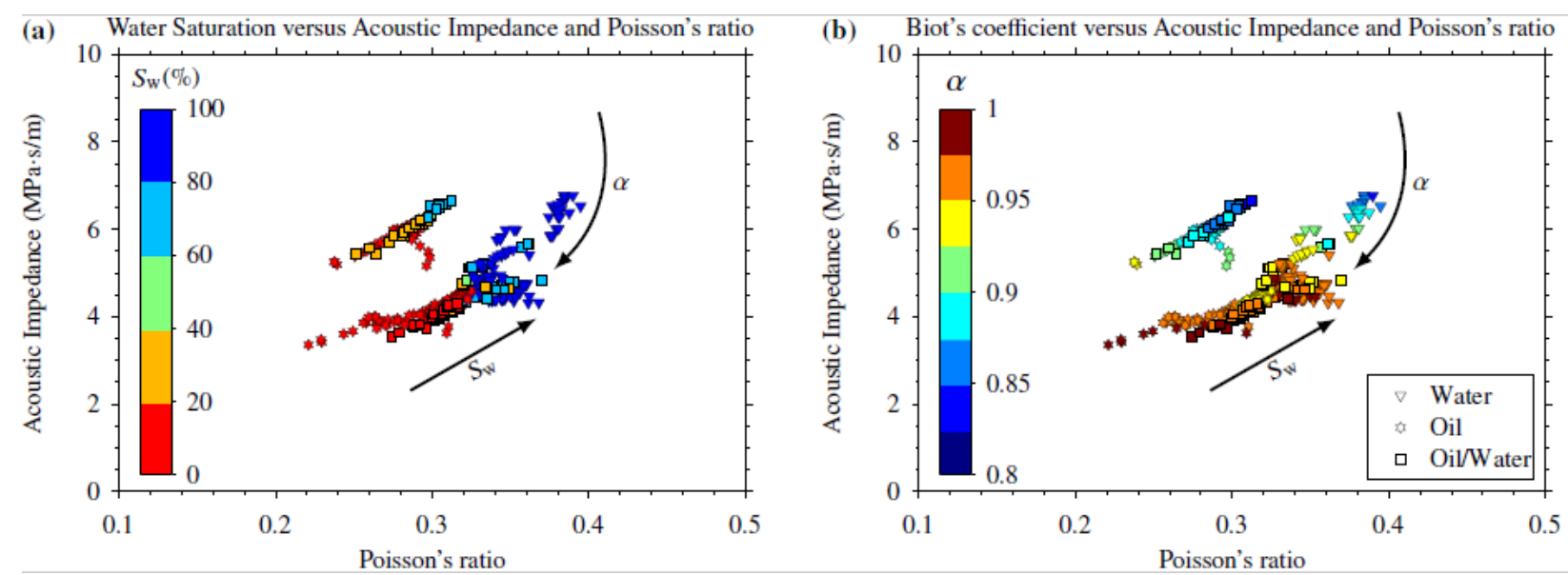

Conflict of Interest and data availability statement: The authors have no conflicts of interest. Research data are not shared.

\section{REFERENCES}

Azeemuddin, M., Scott, T.E., Zaman, M. and Roegiers, J.C. 2001. Stress-dependent Biot's constant through dynamic measurements on Ekofisk chalk. in: Rock mechanics in the national interest, (ed. Elsworth, D., Tinucci, J.P. and Heasley, K.A.), 38th US Rock Mechanics Symposium, American Rock Mechanics Association, pp. 1217-1222.

Alam, M.M., Fabricius, I.L. and Christensen, H.F. 2012. Static and dynamic effective stress coefficient of chalk. Geophysics 77(2), L1-L11.

Andreassen, K.A. and Fabricius, I.L. 2010. Biot critical frequency applied to description of failure and yield of highly porous chalk with different pore fluids. Geophysics 75(6), E205-E213. 
Gram et al.

Baud, P., Vinciguerra, S., David, C., Cavallo, A., Walker, E. and Reuschle, T. 2009.

Compaction and Failure in High Porosity Carbonates: Mechanical Data and Microstructural Observations. Pure and Applied Geophysics 166, 869-898.

Biot, M.A. 1941. General Theory of Three-Dimensional Consolidation. Journal of Applied Physics 12(2), 155-164.

Biot, M.A. 1956. Theory of propagation of elastic waves in a fluid-saturated porous solid. I. Low-frequency range. Journal of the Acoustical Society of America 28, 168-178.

Biot, M.A. and Willis, D.G. 1957. The Elastic Coefficients of the Theory of Consolidation. Journal of Applied Mechanics 24, 594-601.

Christensen, H.F., Hedegaard, K. and Høier, C. 2003. Shear failure induced by waterflooding of a fractured chalk? In: Rock Stress '03:Proceedings of the Second International Symposium on Rock Stress, Kumamoto, Japan, 4-6 November 2003 (ed. K. Sugawara, K., Obara, Y. and Sato, A.) pp. 491-498.

Dean, E.W. and Stark, D.D. 1920. A Convenient Method for the Determination of Water in Petroleum and Other Organic Emulsions. Journal of Industrial \& Engineering Chemistry 12(5), 486-490.

Doornhof, D., Kristiansen, T.G., Nagel, N., Pattillo, P. and Sayers, S. 2006. Compaction and subsidence. Oilfield Review 18, 50-68.

Dunham, R.J. 1962. Classification of carbonate rocks according to depositional texture. In: ofClassification of Carbonate Rocks In: American Association Petroleum Geologists Mememoir 1 (ed, W.E. Ham) pp. 108-121.

Fabricius, I.L., Gommesen, L., Krogsbøll, A.S. and Olsen, D. 2008. Chalk porosity and sonic velocity versus burial depth: Influence of fluid pressure, hydrocarbons, and mineralogy. Bulletin of the American Association of Petroleum Geologists 92(2), 201-223. 
Gram et al.

Fabricius, I.L., Baechle, G.T. and Eberli, G.P. 2010. Elastic moduli of dry and watersaturated carbonates - effect of depositional texture, porosity and permeability. Geophysics 75(3), N65-N78.

Gassmann F. 1951. Elastic waves through a packing of spheres. Geophysics 16(4), 673-685. Gaviglio, P., Bekri, S., Vandycke, S., Adler, P.M., Schroeder, C., Bergerat, F., Darquennes, A. and Coulon, M. 2009. Faulting and deformation in chalk. Journal of Structural Geology 31, 194-207.

Hermansen, H., Landa, G.H., Sylte, J.E. and Thomas, L.K. 2000. Experiences after 10 years of waterflooding the Ekofisk Field, Norway. Journal of Petroleum Science and Engineering 26, 11-18.

Hickman, R. J. 2004. Formulation and Implementation of a Constitutive Model for Soft Rock. Ph.D. dissertation, Virginia Polytechnic Institute and State University, Department of Civil Engineering.

Hirasaki, G.J., Rohan, J.A., Dubey, S.T. and Niko, H. 1990. Wettability Evaluation During Restored-State Core Analysis. Paper SPE 20506, Presented at the Annual Technical Conf. and Exhib. SPE, New Orleans, Sept. 23-26.

Kågeson-Loe, N.M., Jones, M.E., Petley, D.N. and Leddra, M.J. 1993. Fabric evolution during the deformation of chalk. International Journal of Rock Mechanics and Mining Sciences \& Geomechanics Abstracts 30(7), 739-745.

Kristiansen, T.G. 1998. Geomechanical Characterization of the Overburden Above the Compacting Chalk Reservoir at Valhall. SPE/ISRM Rock Mechanics in Petroleum Engineering, Trondheim, Norway, 8-10 July 1998, pp. 193-202. 
Gram et al.

Madland, M.V., Hiorth, A., Omdal, E., Megawati, M., Hildebrand-Habel, T., Korsnes, R.I., Evje, S. and Cathles, L.M. 2011, Chemical alterations induced by rock-fluid interactions when injecting brines in high porosity chalks. Transport in Porous Media 87, 679-702.

Mavko, G., Mukerji, T. and Dvorkin, J. 2009. The Rock Physics Handbook: Tools for Seismic Analysis of Porous Media. Cambridge University Press, 2nd edn.

Megawati, M., Hiorth, A. and Madland, M.V. 2013. The impact of surface charge on the mechanical behavior of high-porosity chalk. Rock Mechanical Engineering 46, 1073 1090.

Meireles, L.T.P., Storebø, E.M. \& Fabricius, I.L. 2020. Effect of electrostatic forces on the porosity of saturated mineral powder samples and implications for chalk strength. Geophysics 85(1), MR37-MR50.

Nagel, N.B. 2001. Compaction and subsidence issues within the petroleum industry: From Wilmington to Ekofisk and beyond. Physics and Chemistry of the Earth, Part A: Solid Earth and Geodesy 26. 3-14.

Nermoen, A., Korsnes, R.I., Storm, E., Stodle, T., Madland, M.V. and Fabricius I.L. 2018. Incorporating electrostatic effects into the effective stress relation - insights from chalk experiments. Geophysics 83(3), MR123-MR135.

Plischke, B. 1994. Finite element analysis of compaction and subsidence - Experience gained from several chalk fields. SPE/ISRM Rock Mechanics in Petroleum Engineering, Delft, The Netherlands, 29-31 August 1994, pp. 795-802.

Røyne, A., Bisschop, J. and Dysthe, D.K. 2011. Experimental investigation of surface energy and subcritical crack growth in calcite. Journal of Geophysical Research: Solid Earth 116 (B4): B04204. 
Gram et al.

Schroeder, C., Bois, A.-P., Maury, V. and Halle, G. 1998. Results of tests performed in laboratory on Lixhe chalk to calibrate water/ chalk models. In: Water/chalk (or collapsible soil) interaction - Part 2 (ed. EurockT98: SPE/ISRM Programme Committee), pp. 505514.

Skempton, A.W. 1961. Effective Stress in Soils Concrete and Rocks. in: Pore Pressure and Suction in Soils, (ed. D. Croney and J.D. Coleman), British National Society of the International Society of Soil Mechanics and Foundation Engineering, pp. 4-16.

Springer, N., Korsbech, U. C. C., and Aage, H. K. 2003. Resistivity index measurement without the porous plate: a desaturation technique based on evaporation produces uniform water saturation profiles and more reliable results for tight North Sea chalk. In: Proceedings International Symposium of the Society of Core Analysts, SCA2003-38 Pau, France 2003, pp. 459-470.Surlyk, F., Dons, T., Clausen, C.K. and Higham, J. 2003. Upper Cretaceous. In: The Millennium Atlas: Petroleum geology of the central and northern North Sea, (ed. D. Evans et al.) Geological Society of London, London, pp. 213-233.

Talesnick, M.L., Hatzor, Y.H. and Tsesarsky, M. 2001. The elastic deformability and strength of a high porosity, anisotropic chalk. International Journal of Rock Mechanics and Mining Sciences 38, 543-555.

Voake, T., Nermoen, A., Korsnes, R.I. and Fabricius, I.L. 2019. Temperature cycling and its effect on stress-strain relationships in high porosity chalks. Journal of Rock Mechanics and Geotechnical Engineering 11, 749-759. 
Gram et al.

Table 1: Petrophysical properties of studied chalk samples.

\begin{tabular}{|c|c|c|c|c|c|c|c|c|c|}
\hline & & & & & Bulk & Liquid & Carbonate & Grain & Water- \\
\hline & Sample & Porosity & Length & Diameter & Density & Permeability & Content & Density & Saturation \\
\hline & Type & $(\%)$ & $(\mathrm{mm})$ & $(\mathrm{mm})$ & $\left(\mathrm{g} / \mathrm{cm}^{3}\right)$ & $(\mathrm{mD})$ & $(\%)$ & $\left(\mathrm{g} / \mathrm{cm}^{3}\right)$ & $(\%)$ \\
\hline \multicolumn{10}{|c|}{ Saturated Samples } \\
\hline \multirow{3}{*}{$\begin{array}{l}\text { High } \\
\text { Porosity }\end{array}$} & Water & 46.6 & 106.18 & 53.64 & 1.921 & 2.17 & 95.0 & 2.711 & 100 \\
\hline & Oil & 46.0 & 107.29 & 53.68 & 1.821 & 2.41 & 93.3 & 2.718 & 0 \\
\hline & Oil/Water & 45.1 & 97.83 & 53.58 & 1.847 & 1.54 & 90.2 & 2.716 & 10 \\
\hline \multirow{3}{*}{$\begin{array}{l}\text { Medium } \\
\text { Porosity }\end{array}$} & Water & 42.3 & 98.83 & 53.93 & 1.993 & 0.79 & 95.9 & 2.710 & 100 \\
\hline & Oil & 42.2 & 107.36 & 53.63 & 1.883 & 1.19 & 88.8 & 2.696 & 0 \\
\hline & Oil/Water & 41.9 & 106.66 & 53.72 & 1.912 & 0.90 & 87.4 & 2.701 & 17 \\
\hline \multirow{3}{*}{$\begin{array}{l}\text { Low } \\
\text { Porosity }\end{array}$} & Water & 36.2 & 107.50 & 53.91 & 2.117 & 0.42 & 88.9 & 2.745 & 100 \\
\hline & Oil & 32.1 & 108.03 & 53.78 & 2.072 & 0.33 & 75.9 & 2.690 & 0 \\
\hline & Oil/Water & 35.0 & 106.78 & 53.67 & 2.036 & 0.26 & 73.6 & 2.692 & 30 \\
\hline \multicolumn{10}{|c|}{ Dry Samples } \\
\hline \multirow{3}{*}{$\begin{array}{l}\text { High } \\
\text { Porosity }\end{array}$} & Dry & 45.8 & 45.63 & 38.07 & 1.485 & - & 92.3 & 2.697 & - \\
\hline & Dry & 47.2 & 61.83 & 38.05 & 1.477 & 1.56 & 90.5 & 2.735 & - \\
\hline & Dry & 45.1 & 58.78 & 24.00 & 1.531 & 1.54 & 88.9 & 2.734 & - \\
\hline \multirow{3}{*}{$\begin{array}{l}\text { Medium } \\
\text { Porosity }\end{array}$} & Dry & 41.7 & 50.18 & 24.09 & 1.658 & 1.21 & 94.3 & 2.748 & - \\
\hline & Dry & 42.4 & 60.07 & 24.20 & 1.590 & 1.55 & 87.4 & 2.713 & - \\
\hline & Dry & 41.4 & 60.67 & 38.24 & 1.582 & 0.91 & 87.2 & 2.685 & - \\
\hline \multirow{3}{*}{$\begin{array}{l}\text { Low } \\
\text { Porosity }\end{array}$} & Dry & 35.6 & 57.72 & 38.08 & 1.805 & 0.80 & 85.4 & 2.773 & - \\
\hline & Dry & 28.3 & 63.05 & 38.21 & 1.946 & 0.44 & 72.1 & 2.707 & - \\
\hline & Dry & 35.4 & 60.98 & 24.38 & 1.774 & 0.53 & 74.7 & 2.709 & - \\
\hline
\end{tabular}

Table 2: Elastic parameters of minerals and fluids at $25^{\circ} \mathrm{C}$ and $1 \mathrm{~atm}$.

\begin{tabular}{|c|c|c|c|c|c|}
\hline & & Bulk & Shear & Dynamic & Kinematic \\
\hline & Density & Modulus & Modulus & Viscosity & Viscosity \\
\hline & $\left(\mathrm{kg} / \mathrm{m}^{3}\right)$ & $(\mathrm{GPa})$ & $(\mathrm{GPa})$ & $(\mathrm{mPa} \cdot \mathrm{s})$ & $\left(\mathrm{mm}^{2} / \mathrm{s}\right)$ \\
\hline Calcite $^{\mathrm{a}}$ & 2710 & 70.8 & 30.3 & - & - \\
\hline Quartz $^{\mathrm{a}}$ & 2650 & 37.0 & 44.7 & - & - \\
\hline $\begin{array}{l}\text { Synthetic Formation } \\
\text { Water }{ }^{\text {b,c }}\end{array}$ & 1015 & 2.37 & - & 0.96 & 0.95 \\
\hline Isopar-L oil ${ }^{b, d}$ & 763 & 1.22 & - & 1.26 & 1.65 \\
\hline \multicolumn{6}{|c|}{${ }^{\mathrm{a}}$ Mean values from citations in Mavko et al. (2009, page 461$)$. } \\
\hline \multicolumn{6}{|c|}{${ }^{6}$ Calculated from empirical relations by Batzle \& Wang (1992) as cited in Mavko et al. (2009). } \\
\hline \multicolumn{2}{|l|}{ 'Salinity: 28.386 ppm. } & & & & \\
\hline \multicolumn{3}{|c|}{ 'ExxonMobil Chemical Isopar-L (EU) datasheet. } & & & \\
\hline
\end{tabular}


Gram et al.

Table 3: Compressional modulus for the elastic (I), elastoplastic (III) and unloading phase.

\begin{tabular}{|c|c|c|c|c|c|c|c|c|c|}
\hline & & & Carbonat & \multicolumn{6}{|c|}{ Compressional Modulus (GPa) } \\
\hline & Sample & Porosity & Content & \multicolumn{2}{|c|}{ Phase I } & \multicolumn{2}{|c|}{ Phase III } & \multicolumn{2}{|c|}{ Unload } \\
\hline & Type & $(\%)$ & $(\%)$ & $\begin{array}{c}\text { Stati } \\
\text { c }\end{array}$ & $\begin{array}{c}\text { Dynami } \\
\text { c }\end{array}$ & $\begin{array}{c}\text { Stati } \\
\text { c }\end{array}$ & $\begin{array}{c}\text { Dynami } \\
\text { c }\end{array}$ & $\begin{array}{c}\text { Stati } \\
\text { c }\end{array}$ & $\begin{array}{c}\text { Dynami } \\
\text { c }\end{array}$ \\
\hline $\begin{array}{c}\text { High } \\
\text { Porosity }\end{array}$ & Water & 46.6 & 95.0 & 1.3 & 10.0 & 0.2 & 11.0 & 18.5 & 11.3 \\
\hline & Oil & 46.0 & 93.3 & 1.8 & 8.1 & 0.2 & 8.5 & 8.3 & 10.0 \\
\hline & $\begin{array}{c}\text { Oil/Wate } \\
\mathrm{r}\end{array}$ & 45.1 & 90.2 & 1.9 & 7.9 & 0.1 & - & 15.4 & - \\
\hline $\begin{array}{c}\text { Mediu } \\
\text { m } \\
\text { Porosity }\end{array}$ & Water & 42.3 & 95.9 & 3.9 & 12.0 & - & - & 6.3 & - \\
\hline & Oil & 42.2 & 88.8 & 2.5 & 9.9 & 0.3 & 10.1 & 6.5 & 10.7 \\
\hline & $\begin{array}{c}\text { Oil/Wate } \\
\mathrm{r}\end{array}$ & 41.9 & 87.4 & 2.6 & 9.5 & 0.3 & 13.0 & 6.0 & 15.4 \\
\hline $\begin{array}{c}\text { Low } \\
\text { Porosity }\end{array}$ & Water & 36.2 & 88.9 & 3.6 & 13.8 & 0.5 & 16.4 & 24.9 & 20.5 \\
\hline & Oil & 32.1 & 75.9 & 6.7 & 17.4 & 0.9 & 18.0 & 12.6 & 18.5 \\
\hline & $\begin{array}{c}\text { Oil/Wate } \\
\mathrm{r}\end{array}$ & 35.0 & 73.6 & 9.5 & 18.2 & - & - & - & - \\
\hline
\end{tabular}

